\title{
Scramble competition by males of the velvet ant Nemka viduata (Hymenoptera: Mutillidae)
}

\author{
Carlo Polidori $^{\mathrm{a}, *}$, Amparo Beneitez ${ }^{\mathrm{b}}$, Josep Daniel Asís ${ }^{\mathrm{b}}$ and José Tormos ${ }^{\mathrm{b}}$ \\ ${ }^{a}$ Departamento de Biodiversidad y Biología Evolutiva, Museo Nacional de Ciencias \\ Naturales (CSIC), C/José Gutiérrez Abascal 2, 28006 Madrid, Spain \\ ${ }^{\text {b } U n i d a d ~ d e ~ Z o o l o g i ́ a, ~ F a c u l t a d ~ d e ~ B i o l o g i ́ a, ~ U n i v e r s i d a d ~ d e ~ S a l a m a n c a, ~}$ \\ 37071 Salamanca, Spain \\ *Corresponding author's e-mail address: cpolidori@mncn.csic.es
}

Accepted 26 October 2012

\begin{abstract}
The mating systems of mutillid wasps have rarely been studied. Here we present information on the mating system of Nemka viduata. At a site in southern Spain, many males of this species were seen flying over host (digger wasp) nest aggregations while searching for females. Male activity was greatest in the early morning and late afternoon, when females were more active searching for hosts, and on days when relatively large numbers of females were active. Males were not territorial but instead attempted to find emerging females before their competitors. As many as six males might arrive at a receptive female more or less simultaneously. Struggles to control access to females continued until one male copulated with the female on the ground or carried it off in flight to a location away from rival males. Male size seems to affect the patrolling behaviour (number of patrolled sites), but there is little evidence of an advantage for larger males, as expected in a scramble competition mating system. Scramble competition mating systems often evolve in species in which large numbers of males compete for scarce receptive females, a factor that makes male territorial defence of large areas highly costly.
\end{abstract}

Keywords

Mutillidae, body size, reproductive biology, scramble competition.

\section{Introduction}

Little is known of the mating behaviour of the Mutillidae, a parasitoid wasp family within the Vespoidea whose members are often referred to as velvet ants. Most researchers have focused on the taxonomy of the group (Schmidt, 2006) or on the hosts parasitized by mutillids, largely other aculeate hymenopterans (Brothers et al., 2000; Polidori et al., 2009a, 2010a). Wingless 
female mutillids search for nests of their hosts, which may be solitary or social species, ground-nesting or wood-nesting. Females usually enter nests when hosts are absent (in the early morning or late afternoon) in order to deposit eggs on the mature larvae or prepupae of their host species (Brothers et al., 2000; Polidori et al., 2009a, 2010a). If discovered near or within a nest, female mutillids may be attacked by the nest owner (Polidori et al., 2009a) but are well protected by their thick cuticle, powerful sting and other adaptations (Schmidt \& Blum, 1977).

Male behaviour is less well studied than that of females (Bayliss \& Brothers, 1996; Tormos et al., 2010) but there are reports of males of some species emerging synchronously with conspecific females (Hennessey, 2002), after which the winged males may search for freshly emerged, wingless females. This pattern is especially likely in aggregations from which many mutillid females may emerge from host nests over the course of the flight season (Polidori et al., 2009a, 2010a). Some observers have suggested that either males or females of some species may stridulate to attract mates (Manley, 1977; Bayliss \& Brothers, 1996) but other than laboratory studies of copulatory behaviour (e.g., Bayliss \& Brothers, 2001; Bergamaschi et al., 2010), many details of the mating systems of mutillids remain unknown. Here we present the results of a field study of the mating system of Nemka viduata (Pallas) a medium-size velvet ant widely distributed in the Mediterranean region (Invrea, 1964). This species is an ectoparasitoid of the immature stages of at least three species of bembecine digger wasps (Crabronidae: Bembecinae) (Grandi, 1951; Tormos et al., 2003).

In this species, as in most mutilids, males are winged and females are apterous. Daily and seasonal activity patterns, spatial distribution and parasitism rate have previously been studied for females of this species (Alicata et al., 1974; Polidori et al., 2010a). However, little is known of male mating tactics (Tormos et al., 2010), a topic that is central to this paper.

\section{Materials and methods}

\subsection{Study area}

The study was carried out at 'La Mallada Larga' of 'Dehesa del Saler' (Valencia, Spain: $39^{\circ} 20^{\prime} \mathrm{N}, 0^{\circ} 40^{\prime} \mathrm{W}$ ) during the Summer of 2008 (July-August). At the study area, a coastal salt marsh with damp sandy soil, $N$. viduata is a 


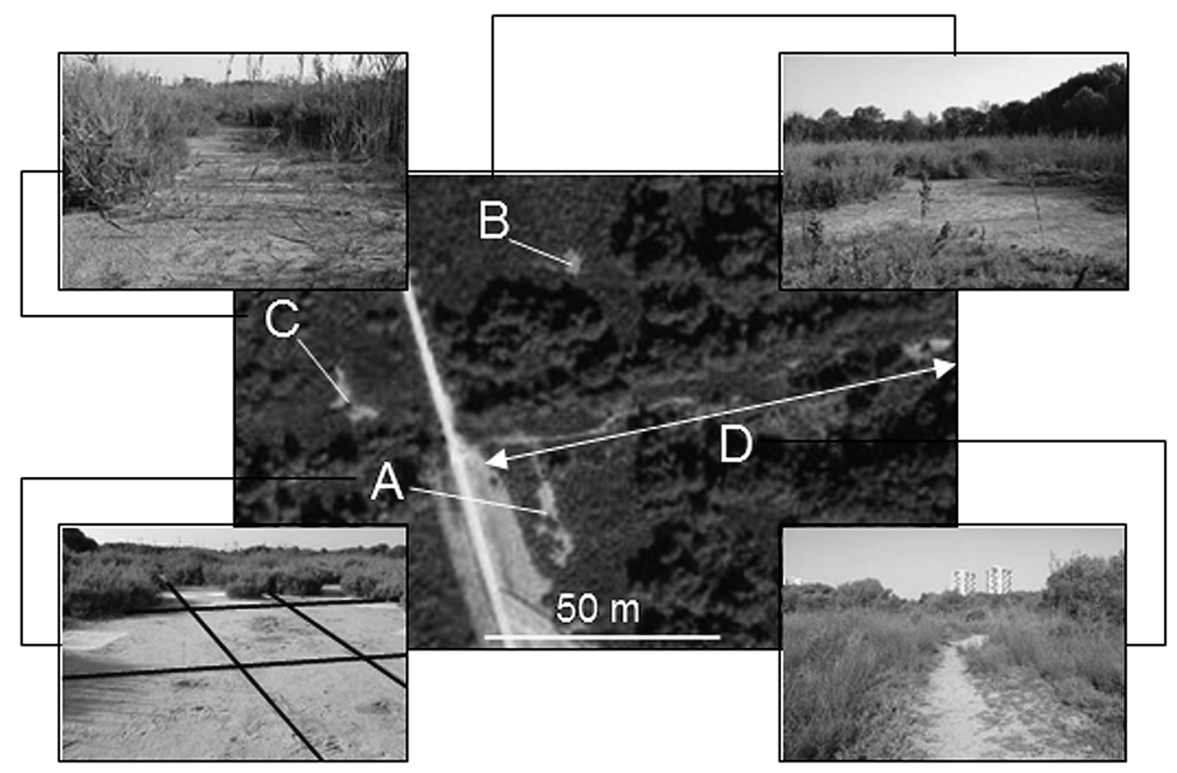

Figure 1. The study area, composed of four nest aggregations of the hosts of Nemka viduata. Sites A, B and C were colonised by the digger wasp Stizus continuus, while site D was colonised by the digger wasp Bembecinus tridens.

parasitoid of the digger wasps Stizus continuus (Klug) and Bembecinus tridens (Fabr.), both nesting abundantly since at least the mid-eighties (Asís et al., 1988; Polidori et al., 2008). Both hosts are solitary, ground-nesting wasps that provision their nests with orthopterans (S. continuous) or homopterans (B. tridens) (Polidori et al., 2007, 2009b).

A total of four sub-areas (hereafter referred to as 'sites') were chosen for the observations and collection of the individuals (Figure 1). Site A was a large nesting area of $S$. continuus (about 300 nests in $300 \mathrm{~m}^{2}$ ). Sites B and $\mathrm{C}$ were also colonised by $S$. continuus but at a lower nest density (about 20 and 30 nests respectively, in $150 \mathrm{~m}^{2}$ each), and they were at $70 \mathrm{~m}$ and $80 \mathrm{~m}$, respectively, from site A; site D was a ground path about $100 \mathrm{~m}$ long and $1.5 \mathrm{~m}$ wide connecting site $\mathrm{A}$ with the sand coastal dunes, and it was colonised by $>100$ B. tridens nests.

\subsection{Activity patterns}

The activity of $N$. viduata males was assessed at site A between 10 and 23 July 2008 by censusing 23 fixed plots of $3 \times 3 \mathrm{~m}$ each day from 07.00 to 20.00 (solar hours) ('patrolling method', PT method) (see Polidori et al., 
2010a). The numbers of host nests recorded in a plot with the PT method ranged from 0 to 27 . However, the number of nests changed across the days of observation as a consequence of the host nesting activity, so that at the end of the study each plot contained on average from $0.1 \pm 0.3$ to $19.7 \pm 6.6$ nests ( $N=14$ days). Each hour, eight of these plots were randomly chosen for data collection (each of the 23 plots was observed $18.3 \pm 3.4$ times), and they were observed for 5 min each, during which time we recorded the number of host nests and the number of $N$. viduata males and females in the plot. For this part of the study, males were not individually marked. These data enabled us to analyse the temporal (per day and per hour of the day) and spatial (per plot) activity of males in relation to the activity of females and to the number of host nests.

\subsection{Individual behaviour and body size}

A total of 18 males from site A, 2 from site B, 5 from site $\mathrm{C}$ and 10 from site $\mathrm{D}$ were individually marked on the thorax with nontoxic colour paints, weighed with an Ohaus Scout Pro electronic balance to the nearest $0.002 \mathrm{~g}$, and then released at the same site they were marked.

Daily from 08.30 to 10.30 and from 18.30 to 20.30 , during the periods of highest male activity (see below), the four sites were censused twice for 15 min each, in a random order, and the presence/absence of marked males was recorded ('whole area marked method', WAM method). These data were collected between 7 and 20 August. At site A the presence/absence of the marked males was assessed also in the 23 plots ( 5 min observations/plot: 'site A marked method', SAM method). These data were collected between 21 and 30 August.

\subsection{Statistical analysis}

The data from the PT method, WAM method, SAM method and male body mass were not normally distributed (Jarque-Bera (JB) test $>100$, $p<0.0001$ ), and hence they were transformed prior to statistical analysis. Data of activity and body mass were transformed as $\ln (x+1)$, while number of host nests, number of plots and number of sites were transformed as $x^{1 / 2}$. Parametric least-squares regressions were used to evaluate the distribution of activity during the day, testing whether the simplest regression model (linear or quadratic) fitted the data distributions (see, for example, Polidori et al., 2009a, 2010a). 
Linear associations were verified with the Pearson correlation (if $N>10$ ) or with the Spearman correlation (if $N<10$ ), and means compared with Student's $t$-test.

A multiple linear regression based on the data from the PT method was performed to look for a significant effect of female activity, number of host nests and plots' identity on the activity of males (transformed values).

The $\chi^{2}$-test was used to test for differences in the number of recaptures for marked males across sites and plots. For plot analysis, the low sample size did not allow the use of the test (expected values $<5$ ) across all 23 plots, thus the plots were divided into three areas (plots 1-8, plots 9-16 and plots 17-23) and the recapture frequencies compared among these three groups of plots. Similarly, because site B and C were much less visited by males (see Results), we chose to compare only the recapture frequencies between sites A and D. For both analyses, we only included the males for which there were enough sightings $(\geqslant 15$ for the plot-group analysis $(N=4)$ and $\geqslant 10$ for the site analysis $(N=8))$.

Mean values in the text are given \pm their standard deviation.

\section{Results}

\subsection{General male behaviour and spatio-temporal activity (PT method)}

Males of $N$. viduata typically flew close to the ground in search of receptive females. In the early morning (07.00-8.00), when the temperature at the site was often about $20^{\circ} \mathrm{C}$ (independent data from 2004-2005, see Polidori et al. 2010a), the males ran over the ground rather than flying over the area. Sometimes they also disappeared below the bushes present in the host nest aggregations. Following individual males while patrolling the area was difficult, and normally we had no chance of recording the specific movements of males over a long time-period. Males were numerous at some periods of the day, with up to 5 males/plot recorded simultaneously in a 5-min observation; however, because at some hours they were rare (see below), the average number per observation event decreased to $0.2 \pm 0.6(N=420)$. Females were much less numerous, with no more than one individual/plot recorded in a 5-min observation, and an average number per observation of $0.1 \pm$ $0.3(N=420)$. Although we did not mark females, it is unlikely that such low numbers depend on female-female competitive interference in the plots, since it was not rare to observe individual females exit from the observed plot 


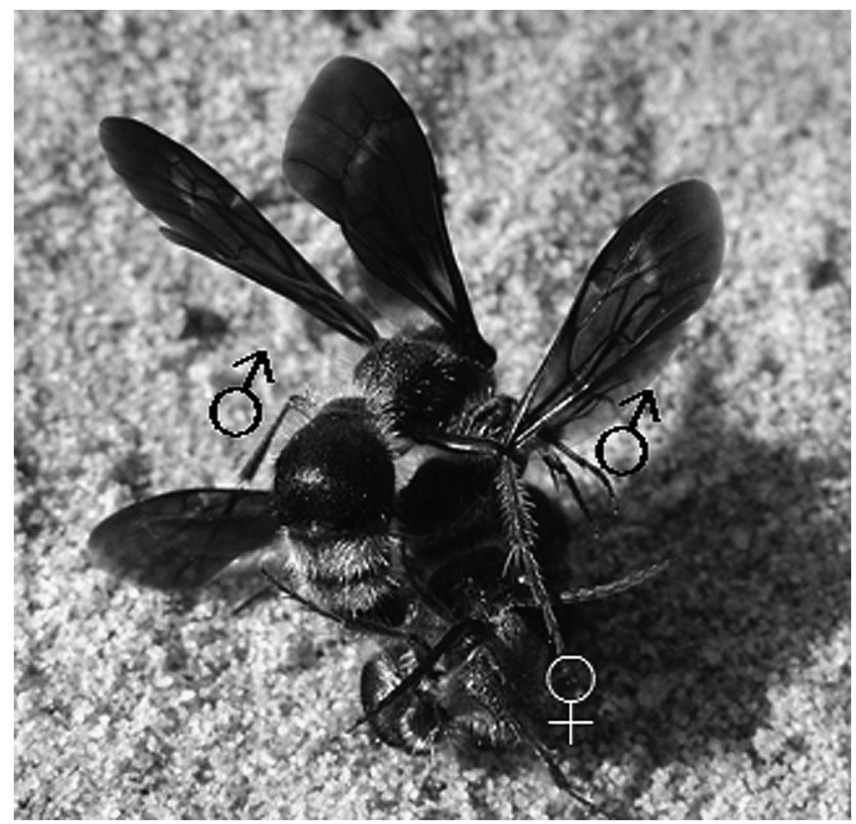

Figure 2. Two males attempting to grasp a female of Nemka viduata.

and enter another one during the 5-min observation. Moreover, unpublished independent data on marked females show a positive correlation between the number of re-captures of marked females and the number of plots where they are re-captured (Polidori et al., unpublished data).

Males (up to six individuals) might grapple with one another for a female, although usually fewer males competed for the same female $(2.7 \pm 1.3$, $N=13$ ) (Figure 2). Although male grappling was recorded on numerous occasions during high activity days and hours, mating was observed very rarely. Of the 13 male-male grapples, eight ended when one male flew off with the female, presumably to mate elsewhere. In three other cases, the grapple apparently broke up after several minutes, without the female being carried off. In the remaining two cases, the grapples broke up and one male mounted the female in situ without the female being carried off, with a short copula lasting 15-30 s. During these two matings, males and females behaved as already described in Tormos et al. (2010).

During the month of July, male and female daily activity were positively correlated (Pearson test, $r=0.66, N=12, p=0.018$ ) (Figure 3a), and because both sexes showed a clear negative quadratic trend across hours 

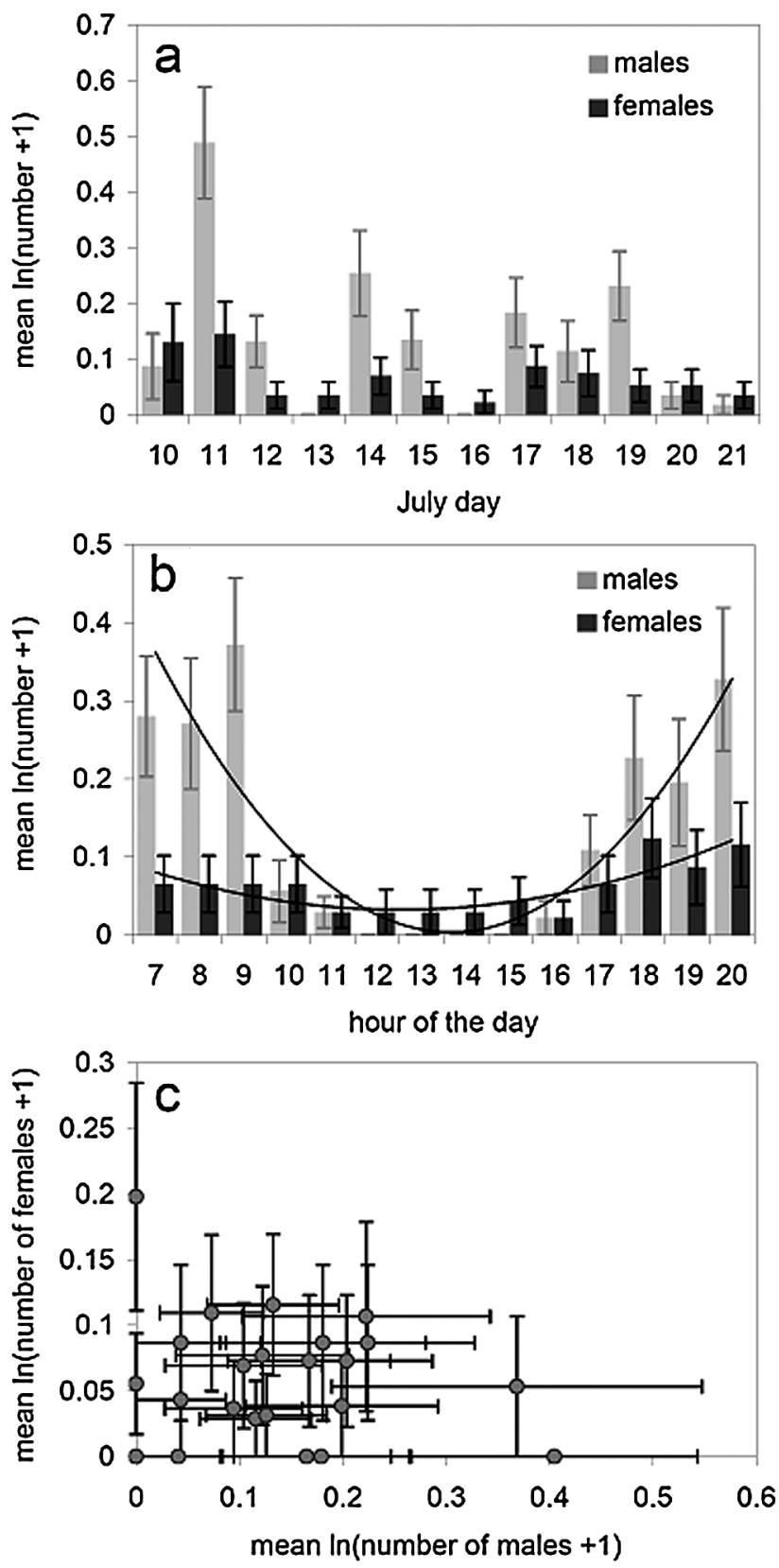
(males: $R^{2}=0.77, N=14, p<0.001$, females: $R^{2}=0.70, N=14, p<$ 0.001 ), their hourly activity rates also were positively correlated (Pearson test, $r=0.73, N=14, p=0.003$ ) (Figure 3b).

Although the temporal patterns of male and female activity were matched, their spatial distributions were not linked. Male activity in plots that were visited at last once by females $(0.25 \pm 0.19, N=18)$ was not higher than in plots that were never visited by females $(0.27 \pm 0.28, N=5)\left(t_{21}=0.43\right.$, $p=0.67)$. Moreover, there was no correlation between male and female activity across the 23 plots (Pearson test, $r=-0.19, N=23, p=0.37$ ) (Figure 3c).

In the multiple regression model $\left(F_{22,419}=2.33, p<0.001\right)$, a significant and positive effect of the plots $4\left(t_{22}=3.67, p<0.0001\right)$ and 18 $\left(t_{22}=2.19, p=0.028\right)$ on male activity was detected. This result is probably independent from the effect of female activity on male activity, which also was positive in the model $\left(t_{1}=2.94, p=0.004\right)$, given that the plots 4 and 18 were not strongly frequented by females (no records for plot 18 and only $0.07 \pm 0.27$ records for plot 4 ). The number of host nests was also associated with male activity, but negatively $\left(t_{1}=-2.96, p=0.003\right)$. Also, in this case, the negative effect of host nests and the preference for certain plots are not related, since plot 4 had many nests $(19.7 \pm 6.6)$ but plot 18 had many fewer nests $(3.64 \pm 0.92)$.

\subsection{Individual behaviour and body size effect (WAM and SAM methods)}

Some males were re-captured more frequently than others during the study although, in general, recapture rate was low. Indeed, of 35 marked males, seven were never recaptured, seven were recaptured only once, and the other males were recaptured from four to 14 times $(8.2 \pm 3.2$ on average) in the whole area (four sites: WAM method). Inside site A, 18 marked males were recaptured, from one to 26 times $(8.7 \pm 7.7$ on average) $(23$ plots: SAM method).

Males (those with at least five sightings, to make the analysis more reliable) patrolled from one to three sites and from four to 13 plots during the

Figure 3. Distribution of Nemka viduata male and female activities throughout July (a) and across daily hours (b), and the relationship between females and males' activities across the 23 plots at site A (average per 5-min census) (c). Regression lines are shown only for the significant trends. Data are expressed as $\ln (x+1)$ because zeros occurred in the sample. Error bars represent standard errors. 

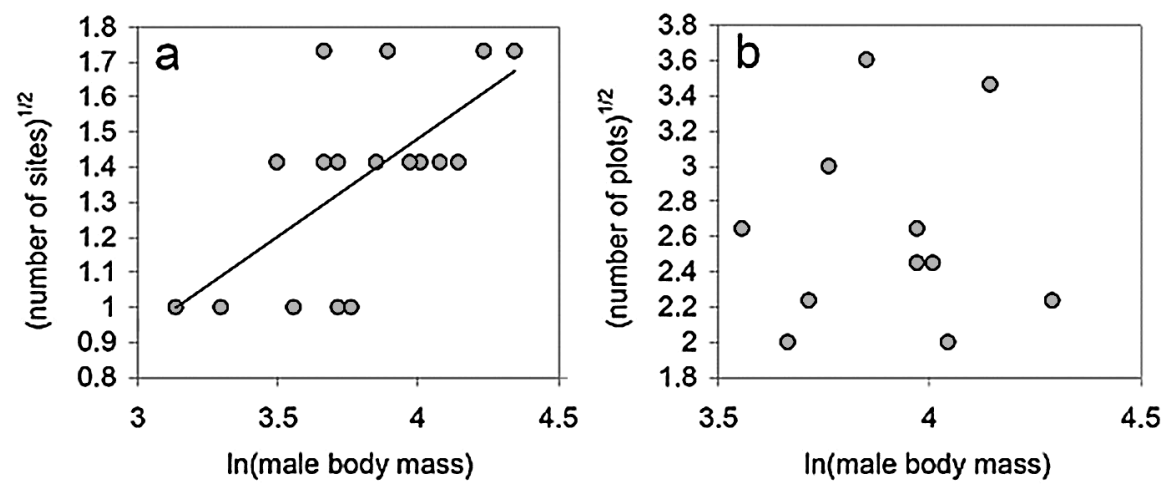

Figure 4. Relationships between transformed body mass of males and transformed number of patrolled sites (a) and plots at site A (b). The trend line in (a) follows the linear model: number of sites $=-0.75+0.56 \ln$ (body mass).

study. Overall, males were more often recaptured in certain large emergence sites (Figure $4 b)\left(\chi_{3}^{2}=139.5, p<0.0001\right)$, with site $\mathrm{A}$ and (to a much lesser extent) site $\mathrm{D}$ being the most frequented ones.

Some individuals showed marked preference for certain plots and certain sites. In particular, two out of four males showed a preference for one plotgroup $\left(\chi_{2}^{2}=8.4, p<0.05 ; \chi_{2}^{2}=15.31, p<0.05\right)$. On the other hand, five out of the eight males preferred to patrol either site $\mathrm{A}$ or site $\mathrm{D}\left(\chi_{1}^{2}=8.2\right.$, $p<0.01 ; \chi_{1}^{2}=8.2, p<0.01 ; \chi_{1}^{2}=17.8, p<0.001 ; \chi_{1}^{2}=13, p<0.001$ $\left.\chi_{1}^{2}=11.6, p<0.01\right)$. There was no evidence that male body size influenced fidelity to a particular site, given the non-significant correlation between the $\chi^{2}$ values and the $\ln$ (body mass) across the eight males (Spearman test, $\rho=0.43, N=8, p=0.30$ ). However, larger males patrolled more sites than smaller males (Pearson test, $r=0.66, N=17, p=0.005$ ) (Figure 4a), but they did not patrol either more or fewer plots than the smaller ones (Pearson test, $r=0.04, N=11, p=0.91$ ) (Figure 4b).

\section{Discussion}

Males of $N$. viduata fly close to the ground searching for receptive females as has been reported for other mutillids such as Lophomutilla corupa Casal (Bergamaschi et al., 2010), and for some apoid wasps (e.g., Thomas \& Nonacs, 2002; Alcock \& Kemp, 2005). During the cooler hours, males seem to fly less and more often run over the ground, as described previously for another mutillid, Tricholabioides thisbe (Peringuey) (Bayliss \& 
Brothers, 1996). When several males fought for a female, either one male carried the female away or a male succeeded in copulating with the female on the ground. In the latter case, males were perhaps too small to lift females in flight. $N$. viduata did not seem to be sexually dimorphic in body mass (Tormos et al., 2010), and previous calculations based on flight muscle ratio (flight muscle mass/body mass) revealed that not all males can actually carry females and that some females cannot be carried by any males (Tormos et al., 2010). Size dimorphism between sexes was suggested to define whether phoresy evolved in the mutillid mating system, being theoretically possible only if females are smaller than males (Nonvellier, 1963; Deyrup \& Manley, 1986). However, even in species with sexes similar in average size, phoresy can occur at least for some male-female combinations (Bayliss \& Brothers, 1996; Tormos et al., 2010).

Flying off with females could be advantageous for males in this species given the large number of competing males. Competition is high not only because a male-biased sex-ratio, but also from the relatively narrow daily temporal window in which males and females are active (early morning and late afternoon), a pattern typical of mutillid wasps irrespective of the temperatures at the reproductive sites (from the hot summers of Michigan, Minnesota and southern Spain sand dune systems to the cool spring of central Italy) (Chapman et al., 1926; Evans, 1982; Polidori et al., 2009a, 2010a, 2012). In addition to an inverse relationship with temperature previously reported for N. viduata female activity (Polidori et al., 2010a) (and, thus, likely occurring also for males, given the very similar daily distribution), the activity of the host species was also negatively associated with that of the parasitoid (Polidori et al., 2010a). Host activity may be a key factor in shaping the daily distribution of females, and in consequence the males.

In contrast to temporal matching, spatial matching between sexes did not occur within host nest aggregations. The most frequented plots by males were not frequented more often by females, and they did not include more host nests. There was even an inverse association between male activity and host nest number. Perhaps males concentrate on plots with more bushes, which could provide sheltered during the periods of highest temperature or at night. In fact, the most visited plots at site A were also partially covered by Arthrocnemum fruticosum (Chenopodiaceae) bushes (see Figure 2 in Polidori et al., 2008), where males were sometimes observed to hide. However, the overall preference for sites A and D likely depends on the much 
higher host nest density (and thus probable higher number of emerging and host-searching mutillid females). Additionally, some individuals showed a marked fidelity for certain plots and certain sites, similar to that reported in some wasps and bees with scramble competition mating systems such as Glenostictia satan Gillaspy (Longair et al., 1987), Palmodes praestans (Kohl) (Alcock \& Kemp, 2005) and Habropoda pallida Timberlake (Alcock \& Buchmann, 2011). In the mason bee Osmia rufa L. such fidelity creates individual home ranges around nesting sites or food plants, and sometimes they partially or totally overlapped (Seidelmann, 1999). Other factors, such as the time cost of patrolling and the number of competitor males, may influence the selection of sites by mate-searching mutillid males. But males do not focus on sites with a particular host species inasmuch as the two most visited sites (A and D) where colonised by different host species.

Whatever the reasons for spatial distribution of males, our results clearly show that males did not establish territories and instead adopt a typical scramble competition strategy (Thornill \& Alcock, 1983). Among the aculeate Hymenoptera, when receptive females are scarce and widely dispersed, males often engage in scramble competition for mates (Thornhill \& Alcock, 1983; Stone et al., 1995; Alcock \& Kemp, 2005; Paxton et al., 2005). On the other hand, when females emerge in clusters or when resources attracting females are aggregated, males usually adopt a female defence or resource defence polygyny strategy through territoriality (Thornhill \& Alcock, 1983). In addition, scramble competition should be favoured when male density is high compared to females (Paxton et al., 2005). As predicted, we found that male density was high (and the sex ratio possibly male biased). The host wasp of $N$. viduata at site A, S. continuus, also exhibits high male density and aggregated nests, although not a male-biased sex ratio (Polidori et al., 2010b). As a matter of fact, males of this species are territorial (Asís et al., 2006). In addition, territoriality could be favoured in S. continuus perhaps because females mate only once, so that males would have few chances to mate if they do not control territories where virgin females emerge. In contrast, females of $N$. viduata may be polyandrous. Some female velvet ants mate more than once (Bergamaschi et al., 2010) while others are monogamous (Brothers, 1972; García et al., 2006). Furthermore, males and females of different species, including $N$. viduata, collected at host nesting sites (thus unlikely to be all freshly emerged and virgin) will mate when put in a Petri dish together (Bayliss \& Brothers, 1996, 2001; Tormos et al., 2010). In case 
of polyandry, males could be more advantaged in patrolling a larger area where a greater number of receptive (virgin or not) females are likely to be intercepted.

Finally, as expected in scramble competition mating systems, large males seem not to mate more often, as selection favours rapid location of mates rather than fighting ability (Thornhill \& Alcock, 1983). Indeed, a lack of advantage (Larsson \& Tengö, 1989; Seidelmann, 1999) or even a disadvantage (Stoks, 2000; Moya-Larano et al., 2002) for large males scrambling to find mates have been reported. Larger males of the bee Anthophora plumipes Pallas, however, tolerate lower temperatures better and can court females under conditions in which smaller males cannot fly, and they can also displace smaller males from favoured flight positions immediately behind females (Stone et al., 1995). We found an effect of body size on patrolling behaviour, which may suggest a possible advantage for large males of $N$. viduata. First, because host size determines female mutillid size (Pitts et al., 2010), larger males could phoretically mate with both females emerging from large hosts (S. continuus) and from small hosts (B. tridens), while smaller males could only carry smaller females. Because $S$. continuus and $B$. tridens nested in different sites, larger males could gain by patrolling the nesting sites of both species. Furthermore, within mating balls, larger $N$. viduata males would be more likely to be able to fly off with large as well as smaller females.

In conclusion, there is more to learn about the evolution of male mating tactics in Hymenoptera but there are many cases of convergent evolution involving $N$. viduata and ground-nesting bees and other wasps in which males try to outrace rivals to emerging females rather than engaging in costly defence of even a small portion of the emergence area. Should a male encounter a female, he then attempts to defend her, an attempt with large benefits, namely exclusive access to a receptive female.

\section{Acknowledgements}

Thanks are due to the Town Hall of Valencia and the Generalitat Valenciana for issuing the permits necessary to carry out part of this work in La Mallada Larga (El Saler). We are indebted to John Alcock, who gave important suggestions and made many editorial corrections on an early version of the ms. Thanks are due to Micol Montagna, who helped with field data collection, and to Davide Santoro, who kindly provided the picture used in 
Fig. 2. The research was supported by funding from the Junta de Castilla y León (SA094A09) and by a post-doctoral contract to C.P. (Program JAEDoc 'Junta para la Ampliación de Estudios' funded by the Spanish Research Council (CSIC) and the FSE). Experiments comply with the current Spanish law.

\section{References}

Alcock, J. \& Kemp, D.J. (2005). The scramble competition mating system of the sphecid wasp, Palmodes praestans (Kohl). — J. Nat. Hist. 39: 2809-2814.

Alcock, J. \& Buchmann, S. (2011). The mating system of Habropoda pallida Timberlake (Anthophorinae: Apidae). — J. Ins. Behav. 24: 348-362.

Alicata, P., Caruso, D., Costa, G. \& Motta, S. (1974). Richerche eco-etologiche sulla fauna delle dune costiere di Porto Palo (Siracusa). I. Smicromyrme viduata (Pall.) (Hymenoptera, Mutillidae): Ritmi di attivita migrazioni e accoppiamento. - Animalia 1: 89-108.

Asís, J.D., Tormos, J. \& Jiménez, R. (1988). Contribution to the study of the biology of Stizus continuus (Hymenoptera: Sphecidae). — Entomol. News 99: 199-206.

Asís, J.D., Tormos, J. \& Gayubo, S.F. (2006). Territorial dynamics and contest behaviour in the solitary wasp Stizus continuus (Hymenoptera: Apoidea: Crabronidae). - Behaviour 143: 83-104.

Bayliss, P.S. \& Brothers, D.J. (1996). Biology of Tricholabiodes Radoszkowski in southern Africa, with a new synonymy and review of recent biological literature (Hymenoptera: Mutillidae). — J. Hym. Res. 5: 249-258.

Bayliss, P.S. \& Brothers, D.J. (2001). Behaviour and host relationship of Dolichomutilla sycorax (Smith) (Hymenoptera: Mutillidae, Sphecidae). — J. Hym. Res. 10: 1-9.

Bergamaschi, A., Cambra, R. \& Melo, G. (2010). Male description and host record for Lophomutilla corupa Casal, 1968 (Hymenoptera: Mutillidae), with behavioural notes on mating behaviour and host nest attacks. - J. Nat. Hist. 44: 2597-2607.

Brothers, D.J. (1972). Biology and immature stages of Pseudomethoca frigida F., with notes on other species (Hymenoptera: Mutillidae). — Univ. Kans. Sci. Bull. 50: 1-38.

Brothers, D.J., Tschuch, G. \& Burger, F. (2000). Associations of mutillid wasps (Hymenoptera, Mutillidae) with eusocial insects. — Insect. Soc. 47: 201-211.

Chapman, R.N., Mickel, C.E., Parker, J.R., Miller, G.E. \& Kelly, E.G. (1926). Studies in the ecology of sand dune instects. - Ecology 7: 416-426.

Deyrup, M. \& Manley, D. (1986). Sex-biased size variation in velvet ants (Hymenoptera, Mutillidae). - Fla. Entomol. 69: 327-335.

Evans, D.A. (1982). Diurnal and seasonal activity of female mutillids on a Michigan sand flat (Hymenoptera: Mutillidae). — Great Lakes Entomol. 15: 213-216.

Garcia, E.Q., Cambra, R. \& Melo, G.A.R. (2006). Sexual associations for two species of mutillid wasps (Hymenoptera, Mutillidae), with the description of a new species of Anomophotopsis. — Rev. Bras. Entomol. 50: 379-384. 
Grandi, G. (1951). Entomologia. — Edagricole, Bologna.

Hennessey, R.D. (2002). Population-level characteristics of Dasymutilla nigripes, D. vesta, and Timulla vagans (Hymenoptera: Mutillidae). — Fla. Entomol. 85: 245-253.

Invrea, F. (1964). Mutillidae-Myrmosidae, Fauna d'Italia, Vol. 5. - Calderoni, Bologna.

Larsson, F.K. \& Tengö, J. (1989). The effects of temperature and body size on the mating pattern of a gregariously nesting bee, Colletes cunicularius (Hymenoptera: Colletidae). — Ecol. Entomol. 14: 279-286.

Longair, R.W., Cane, J.H. \& Elliot, L. (1987). Male competition and mating behavior within mating aggregations in Glenostictia satan Gillaspy (Hymenoptera: Sphecidae). J. Kansas Entomol. Soc. 60: 264-272.

Manley, D.G. (1977). Notes on the courtship and mating of Dasymutilla Ashmead (Hymenoptera: Mutillidae) in Calif. — Southw. Nat. 21: 543-559.

Moya-Larano, J., Halaj, J. \& Wise, D. (2002). Climbing to reach females: Romeo should be small. - Evolution 56: 420-425.

Nonvellier, G. (1963). Quelle est la cause de la rareté des mutillides? Resultats de l'étude de certaines de leurs caracteres biologiques et ecologiques. — Mem. Soc. Entomol. It. 62: 24-57.

Paxton, R.J. (2005). Male mating behaviour and mating systems of bees: an overview. Apidologie 36: 145-156.

Pitts, J.P., Tanner, D., Waldren, G.C. \& Parker, F.D. (2010). Facultative size-dependant sex allocation in Sphaeropthalma pensylvanica Lepeletier (Hymenoptera: Mutillidae) with new host records. - J. Kans. Entomol. Soc. 83: 68-75.

Polidori, C., Zangheratti, V., Martinoli, A. \& Andrietti, F. (2007). Temporal transition of nesting activities in the digger wasp, Bembecinus tridens (Hymenoptera: Crabronidae). — It. J. Zool. 74: 265-275.

Polidori, C., Mendiola, P., Asís, J.D., Tormos, J., Selfa, J. \& Andrietti, F. (2008). Femalefemale attraction influences nest establishment in the digger wasp Stizus continuus (Hymenoptera: Crabronidae). - Anim. Behav. 75: 1651-1661.

Polidori, C., Borruso, L., Boesi, R. \& Andrietti, F. (2009a). Segregation of temporal and spatial distribution between kleptoparasites and parasitoids of the eusocial sweat bee, Lasioglossum malachurum (Hymenoptera: Halictidae, Mutillidae). — Entomol. Sci. 12: 116-129.

Polidori, C., Mendiola, P., Asís, J.D., Tormos, J., García, M.D. \& Selfa, J. (2009b). Predatory habits of the grasshopper-hunting wasp Stizus continuus (Hymenoptera: Crabronidae): diet preference, predator-prey size relationships and foraging capacity. - J. Nat. Hist. 43: 2985-3000.

Polidori, C., Mendiola, P., Asís, J.D., Tormos, J. \& Selfa, J. (2010a). Temporal asynchrony and spatial co-occurrence with the host: the foraging patterns of Nemka viduata, a parasitoid of digger wasps (Hymenoptera: Mutillidae and Crabronidae). — J. Ethol. 28: 353-361.

Polidori, C., Giordani, I., Mendiola, P., Asís, J.D., Tormos, J. \& Selfa, J. (2010b). Emergence and dispersal relative to natal nest in the digger wasp Stizus continuus (Hymenoptera: Crabronidae). - C.R. Biol. 333: 255-264. 
Polidori, C., Beneitez, A., Asís, J.D., Gayubo, S.F. \& Tormos, J. (2012). Predicting activity patterns from resource exploitation in guilds of digger wasps' natural enemies. - Adv. Sci. Lett., in press.

Seidelmann, K. (1999). The race for females: the mating system of the red mason bee, Osmia rufa (L.) (Hymenoptera: Megachilidae). — J. Insect Behav. 12: 13-25.

Schmidt, J.O. (2006). Hot spots around the world - diversity, density, and longevity of mutillid wasps. - The 2006 ESA Annual Meeting, December 10-13, 2006.

Schmidt, J.O. \& Blum, M.S. (1977). Adaptions and responses of Dasymutilla occidentalis (Hymenoptera, Mutillidae) to predators. — Entomol. Exp. Appl. 21: 99-111.

Stoks, R. (2000). Components of lifetime mating success and body size in males of a scrambling damselfly. - Anim. Behav. 59: 339-348.

Stone, G.N., Loder, P.M.J. \& Blackburn, T.M. (1995). Foraging and courtship behaviour in males of the solitary bee Anthophora plumipes (Hymenoptera: Anthophoridae): thermal physiology and the roles of body size. - Ecol. Entomol. 20: 169-183.

Thomas, J.F. \& Nonacs, P. (2002). Size dimorphism and male aggregation behavior in the sand wasp, Steniolia nigripes (Sphecidae: Bembecinae). — Sociobiology 40: 317-323.

Thornill, R. \& Alcock, J. (1983). The evolution of insect mating systems. - Harvard University Press, Cambridge.

Tormos, J., Asís, J.D. \& Gayubo, S.F. (2003). Description of the mature larva of Nemka viduata (Pallas) (Hymenoptera: Mutillidae: Mutillinae), a parasitoid of Stizus continuus (Klug) (Hymenoptera: Crabronidae: Bembicinae). — J. Entomol. Sci. 38: 502-510.

Tormos, J., Asís, J.D., Polidori, C., Benéitez, A. \& Storino, G. (2010). The mating behaviour of the velvet ant, Nemka viduata (Hymenoptera: Mutillidae). — J. Insect Behav. 23: 117127. 